\title{
Stage IIB Fallopian Tube Cancer AJCC v8
}

National Cancer Institute

\section{Source}

National Cancer Institute. Stage IIB Fallopian Tube Cancer A/CC V8. NCI Thesaurus. Code C139990.

Stage IIB includes: T2b, N0, M0. T2b: Fallopian tube cancer with tumor extension to and/or implants on other pelvic tissues. N0: No regional lymph node metastasis. M0: No distant metastasis. (AJCC 8th Ed.) 